\title{
Isolated Arteritis of Both Lower Limbs
}

\section{Miroslav Průcha ${ }^{1}$,Alena Šnajdrová ${ }^{2}$, Pavel Zdráhal $^{3}$}

${ }^{1}$ Department of Clinical Biochemistry, Haematology and Immunology,

Na Homolce Hospital, Prague, Czech Republic;

${ }^{2}$ Department of Radiology, Na Homolce Hospital, Prague, Czech Republic;

${ }^{3}$ Department of Vascular Surgery, Na Homolce Hospital, Prague, Czech Republic

Received November 22, 2017; Accepted March 19, 2018.

Key words: Arteritis - Lower limbs - Diagnostics - Therapy

Abstract: Isolated arteritis of the lower limb vessels is an extremely rare condition. The use of modern vascular imaging techniques substantially facilitates and accelerates the diagnostics. In the isolated lower limb arteritis, it is always necessary to exclude Takayasu's and giant-cell arteritis. We present the case of a female patient with an isolated lower extremity arteritis without any other symptoms of systemic vascular damage or systemic autoimmune disease. Immunosuppressive therapy is obligatory in this case. Interdisciplinary co-operation is required for rapid diagnosis and successful therapy. Our patient has consented to the publication of this report.

This study was supported by an MH CZ - DRO (Nemocnice Na Homolce - NNH, 00023884), IG144101.

Mailing Address: Assoc. Prof. Miroslav Průcha, MD., PhD., Department of Clinical Biochemistry, Haematology and Immunology, Na Homolce Hospital, Roentgenova 2, 15030 Prague 5, Czech Republic; Phone:+420 257273 051; e-mail: miroslav.prucha@homolka.cz 


\section{Introduction}

Isolated arteritis of the vessels of the lower limbs is a rare condition. Impairment of the lower limb arteries usually occurs in connection with Takayasu's arteritis (TA) or giant-cell arteritis (GCA). The clinical symptomatology brings the patients to the vascular surgery or cardiovascular departments. Differential diagnosis must be applied to distinguish between impairment caused by arteriosclerotic disease and occurrence of arteritis in systemic autoimmune disease. Modern imaging techniques provide an adequate means of verifying the clinical symptomatology. The treatment consists of a combination of corticosteroids, immunosuppressive therapy and, if needed, surgical intervention by vascular surgeons. Where such surgical treatment is not possible, there is the option of interventional angioplasty. Combination of these procedures leads to a marked improvement in the efficacy of the treatment and patient prognosis.

\section{Case report}

A 58-year-old female patient with bilateral lower extremity claudication was referred to the Department of Vascular Surgery. From patient history: She suffered for pollinosis, bronchial asthma, had a medication for hypertension. She did not smoke. Subjectively: In the last month, pain in both lower limbs, more on the left, painful also during the night - the patient holds the limb suspended. Bilateral claudication after walking $50 \mathrm{~m}$. The difficulties started a month ago together with night sweats, muscle and joint pain.

Objective finding: height: $152 \mathrm{~cm}$, weight: $55.0 \mathrm{~kg}$, bilateral blood pressure $140 / 85 \mathrm{~mm} \mathrm{Hg}$, the pulse was $82 / \mathrm{min}$. Palpable pulsation of common femoral arteries (CFA) bilaterally; further towards the periphery not palpable bilaterally; the toes are cold, pink, without defects. Laboratory findings: erythrocyte sedimentation rate (ESR) $120 \mathrm{~mm} / \mathrm{h}$, C-reactive protein (CRP) $25 \mathrm{mg} / \mathrm{l}$, haemoglobin level $115 \mathrm{~g} / \mathrm{l}$, white blood cell count (WBC) 11.100 cells $/ \mathrm{mm}^{3}$, platelet count $483.000 / \mathrm{mm}^{3}$, factor $V$ activity $152 \%$, factor VII activity $133 \%$, factor VIII activity $289 \%$, immunoELFO: polyclonal hypergammaglobulinemia, $\lg \mathrm{g} 20.8 \mathrm{~g} / \mathrm{l}, \lg \mathrm{g} 1, \lg \mathrm{g} 2$, $\lg \mathrm{g} 4$, $\lg \mathrm{A}$, IgM within the norm, elevated lgG3 $1.95 \mathrm{~g} / \mathrm{l}$, elevated C3 $1.73 \mathrm{~g} / \mathrm{l}$, and C4 $0.59 \mathrm{~g} / \mathrm{l}$, positive acute phase reactants - orosomucoid $2.0 \mathrm{~g} / \mathrm{l}$, haptoglobin $3.15 \mathrm{~g} / \mathrm{l}$, positive antinuclear antibody (ANA) 1:80, extractable nuclear antibodies (ENA), anti-ds DNA and anti-neutrophil cytoplasmic antibodies (ANCA) negative. Lower limbs ultrasound: superficial femoral artery (SFA) almost obliterated, hyperechogenic wall, flow up to $30 \mathrm{~cm} / \mathrm{s}$, venous system freely patent, normal signal, compressible walls, correct augmentation manoeuvres, peripheral blood pressure on right lower leg (RLL): dorsalis pedis artery (DPA) $35 \mathrm{~mm} \mathrm{Hg}$, index 0.22 , posterior tibial artery (PTA) $60 \mathrm{~mm} \mathrm{Hg}$, index 0.38; left lower leg (LLL): DPA $35 \mathrm{~mm} \mathrm{Hg}$, index 0.22, PTA 40, index 0.20 , pressure at the big toes was low - could not be measured. Computer tomography-arteriography (CT-AG) showed multiple diffusion stenosis of the femoral arteries. Stenosis and occlusions of crural arteries bilaterally, 
correlating with CT sites of adventitial infiltrates. The finding is highly suspected as multicentric bilateral peripheral arteritis. Positron emission tomography/computer tomography (PET/CT): inflammatory impairment of the large arteries of both lower limbs with the finding concentrated along the entire course of both superficial femoral arteries. No other positive finding of metabolic activity in other large arteries. Complex investigation of our patient including CT-AG and PET/CT did not show any damage to other than lower limb arteries. We introduced therapy a combination of corticosteroids - $32 \mathrm{mg}$ methylprednisolon, azathioprine $100 \mathrm{mg}$ and acetylsalicylic acid $200 \mathrm{mg} / \mathrm{day}$. After a mere three weeks, ESR was within the norm, CRP negativised, blood count normalised. Clinically, the patient reported partial relief; walked without claudication 150-200 metres and was not woken at night by pain. We gradually reduced the dose of corticosteroids. The objective finding continued to be without positive pulsations from the knees down bilaterally. Ultrasound after 5 months: common femoral arteries (CFA) without changes bilaterally, popliteal arteries (PA) trunks patent bilaterally. RLL: hairline diffuse narrowing of superficial femoral arteries, image of concentric hypoechogenic thickening of the wall popliteal arteries (PA) and tibioperoneal trunks (TPT)

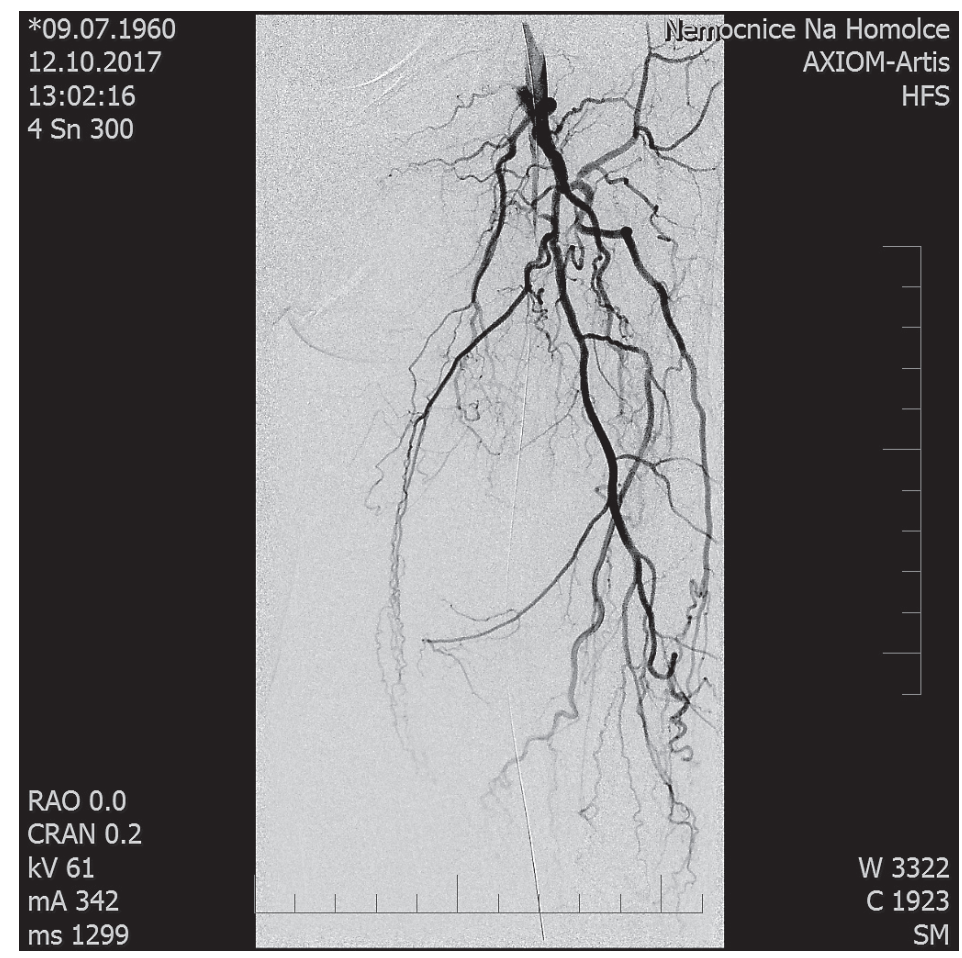

Figure 1 - Left lower leg before percutaneous transluminal angioplasty. 
patent. PTA detectable beyond the inner ankle. LLL: obliteration of the SFA in the thigh popliteal artery (PA) from the collaterals - here partly regressed finding. On the periphery, only weakly detectable distal posterior tibial arteries (PTA). On ultrasound, the finding is without marked improvement compared to the AG investigation in August 2016; the finding is comparable, with small deviations, with the AG investigation. In the effort to influence vascular hyperproliferation, we replaced the combination of corticosteroids and azathioprine with cyclophosphamide, dose $600 \mathrm{mg}$, administered $3 \times$ in three-week interval. This therapy, too, did not lead to any change in the clinical status or during the following imaging investigations: multilevel bilateral diffuse stenosis and SFA obliteration and occlusions of crural arteries; PA filling from collaterals bilaterally; detectable PTA bilat. beyond the ankle. The finding is long-term stationary. After evaluating the clinical status and the result of the imaging investigation we decided to perform percutaneous transluminal angioplasty (PTA) using balloon dilation angioplasty with paclitaxel, first on one and one month later on the other lower limb, with a favourable clinical effect (Figures 1 and 2). Peripheral arteries - FSA, PA and PTA left, and FSA, PA, PTA and fibular artery (FA) right - were made patent in both limbs.

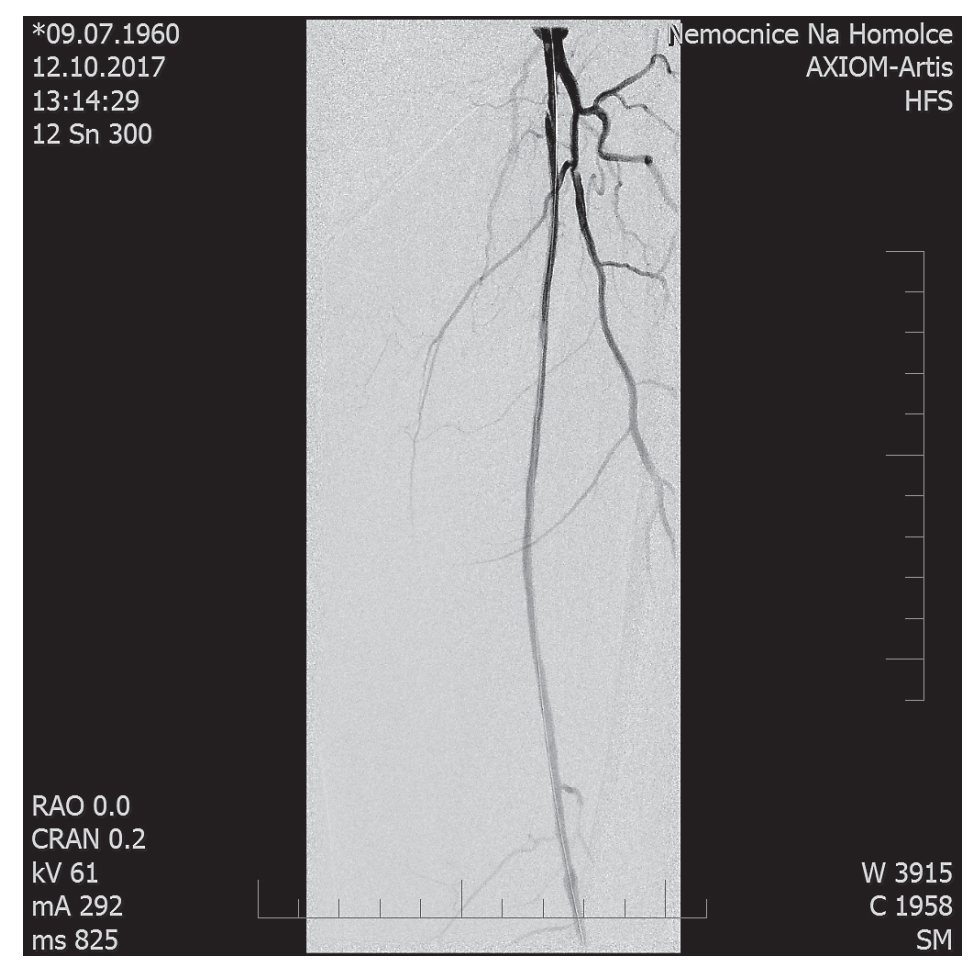

Figure 2 - Left lower leg after percutaneous transluminal angioplasty. 


\section{Discussion}

Isolated arteritis of both lower limbs is a rare disease. Arteritis of the lower limbs occurs most frequently in connection with Takayasu's arteritis or giantcell Horton's arteritis (Kermani et al., 2009; Assie et al., 2011; Sigl et al., 2014). We focused on the possibility of TA or GCA with or without connection with a systemic autoimmune disease. It is necessary to stress, that complex investigation of our patient, including CT-AG and PET/CT, did not show any damage to other than lower limb arteries. So our patient did not meet the criteria of large vessel vasculitis typical for this age - GCA. We excluded rare case of polyarteritis nodosa vasculitis mostly affecting the skeletal leg muscles (Khellaf et al., 2007). Similarly as in the GCA or TA, the treatment of choice is the corticosteroid and/or immunosuppressive therapy. An alternative may be the combination of systemic corticosteroids and azathioprine, which we used. In the case of unsuccessful immunosuppressive therapy, the treatment with tocilizumab or rituximab is possible (Stagnaro et al., 2015). Tocilizumab is a humanized anti-human IL-6 receptor antibody that binds to soluble and membrane-bound IL-6 receptor. Rituximab is an anti-CD20 monoclonal antibody that depletes $B$ cells and is often used in the treatment of non-Hodgkin's lymphoma and B-cell leukemias. Our treatment had a partial effect - the disappearance of positivity of inflammatory parameters - but did not lead to the disappearance or significant retreat of hyperproliferation in the affected vessels that would allow restoration of flow. An important factor of the favourable effect of immunosuppressive therapy was gaining time for setting up collateral circulation, with the final consequence of the patient avoiding amputation of the limbs. We tried to affect the hyperproliferation by administering cyclophosphamide, which is used with relative success in the treatment of vasculitis (de Boysson et al., 2013; Roberts and Clifford, 2017). This therapy, too, had not the desired effect. That is why we decided to perform percutaneous transluminal angioplasty, which was successful. Arterial flow was restored down to the periphery in both lower limbs and the clinical symptomatology disappeared. In this context it is necessary to mention the possibility of locally influencing the vascular architecture with the help of PTA (Barra et al., 2017). Drug-eluting balloons (DEBs) are effective at reducing intimal hyperplasia after angioplasty of the superficial femoral artery, infrapopliteal circulation, and arteriovenous fistulas. In our patient we applied endovascular intervention with a paclitaxel drug eluting balloon. Paclitaxel is a mitotic inhibitor with effect on cellular proliferation. The comparison between a standard balloon dilator without the drug and balloon with paclitaxel in patients with lower limb peripheral arterial occlusion disease has shown higher efficacy of the balloon with paclitaxel in the prevention of restenosis of the treated arteries (Kinstner et al., 2016). The presented case study is an example of successful inter-disciplinary cooperation in the diagnosis and treatment of large artery vasculitis. 


\section{References}

Assie, C., Janvresse, A., Plissonier, D., Levesque, H., Marie, I. (2011) Long-term follow-up of upper and lower extremity vasculitis related to giant cell arteritis. A series of 36 patients. Medicine 90, 40-51.

Barra, L., Liang, P., Benseler, S. M., Cabral, D. A., Mah, A. F., Li, Y., Milman, N., Twilt, M., Yacyshyn, E., Pagnoux, C. (2017) Variations in the clinical practice of physicians managing Takayasu arteritis: a nationwide survey. Open Access Rheumatol. 9, 91-99.

de Boysson, H., Boutemy, J., Creveuil, C., Ollivier, Y., Letellier, P., Pagnoux, C., Bienvenu, B. (2013) Is there a place for cyclophosphamide in the treatment of giant-cell arteritis? A case series and systematic review. Semin. Arthritis Rheum. 43, 105-112.

Kermani, T. A., Matteson, E. L., Hunder, G. G., Warrington, K. J. (2009) Symptomatic lower extremity vasculitis in giant cell arteritis: a case series. J. Rheumatol. 36, 2277-2283.

Khellaf, M., Hamidou, M., Pagnoux, C., Michel, M., Brisseasu, J. M., Chevallier, X., Cohen, P., Guillevin, L., Godeaus, B. (2007) Vasculitis restricted to the lower limbs: a clinical and histopathological study. Ann. Rheum. Dis. 66, 554-556.

Kinstner, C. M., Lammer, J., Willfort-Ehringer, A., Matzek, W., Gschwandtner, M., Javor, D., Funovics, M., Schoder, M., Koppensteiner, R., Loewe, C., Ristl, R., Wolf, F. (2016) Paclitaxel-eluting balloon versus standard balloon angioplasty in in-stent restenosis of the superficial femoral and proximal popliteal artery: 1-year results of the PACUBA trial. JACC Cardiovasc. Interv. 9, 1386-1392.

Roberts, J., Clifford, A. (2017) Update on the management of giant cell arteritis. Ther. Adv. Chronic Dis. 8, 69-79.

Sigl, M., Hsu, E., Scheffel, H., Haneder, S., Rümenapf, G., Amendt, K. (2014) Lower extremity vasculitis in giant cell arteritis: Important differential diagnosis in patients with lower limb claudication. Vasa 43, 326-336.

Stagnaro, C., Cioffi, E., Talarico, R., Della Rossa, A. (2015) Systemic vasculitides: a critical digest of the most recent literature. Clin. Exp. Rheumatol. 33, 145-154 (Suppl. 89). 